\section{非atbolong in 1800.}

By D'ARCY POWER, M.A., M.B.Oxon., F.R.C.S., Assistant Surgeon to St. Bartholomew s Hospital, London.

Ir is perhaps difficult to say whether a greater advance in pathology was made between the years 1700 and 1800 , or between 1800 and 1900 . The workers of the eighteenth century swept away mystical pathology, which owed its birth as much to an ignorance of physics and chemistry as to faulty observation. The workers of the nineteenth century have collected an enormous number of isolated observations, made possible by improvements in physical science, but no master mind has jet appeared to correlate and subordinate these facts, whilst in some departments, notably in pathological chemistry, we have still as much to learn as had our ancestors a century since in the science of chemistry itself.

A hundred years ago modern pathology was in its infancy, but its students had begun to place the new science upon a firm footing of morbid anatomy. The Hunters bequeathed their school and methods to Matthew Baillie, a most worthy disciple and distinguished physician. In I793 Baillie published The Morbid Anatomy of Scme of the Most Important Parts of the Human Body, which he illustrated in I799 by $A$ Series of Engravings representing every Diseased Change of Structure to which the Internal and more Important Parts of the Body are Subject. The two books long served as textbooks of pathology, and a short analysis of their contents will best show wherein we have gained knowledge since they were pabiished.

\section{Terminologr.}

The first thing which strikes a reader of the Morbid Anatomy is the faultless English in which it is written and the easiness of the style. There are no cumbrous pathological terms; inflammation of the liver is not a hepatitig, nor is dropsy of the kidney a hydronephrosis. A few words differ from those now in use : thus, venous is always "veinal," endemic is "endemial," curdy is "curdly," and tuberculous is, of course, "scrofulous," tubercle being employed throughout in its anatomical sense of nodule rather than in the restricted specific sense it now has. Although Dr. Baillie was Snell Exhibitioner of Balliol College, Oxford, he writes "schirrus," still a stumbling-block to students, and "apthæ" -mistakes which are to be excused, perhaps, by the passage in his autobiography which says: "I went to the Latin School at Hamilton before I was quite 7 years old, and remained there six years. The master of the school was named Whale. He was an excellent Latin scholar, but was not very thoroughly acquainted with the Greek, although he had enough of the latter language for the creditable teaching of his school."

The arrangement of the book is essentially anatomical. The matters dealt with are matters capable of being shown by dissection. There is very little theory and there are no generalisations. Baillie, as the nephew, heir, and pupil of the Hunters, often quotes the opinions of his relatives, and always with the greatest respect. John Hunter he epeaks of as "Mr. Hunter, an anatomist whose opinion is of great weight," whilst William Hunter is always mentioned as "the late Dr. Hunter." The work is essentially modern in tone, but occasional glimpses are afforded of the time at whlch it was written, as when arsenic is said to be "the poison most frequently taken," and it is suggested that "every person is acquainted with the appearance of the mucus of the nose when dried," for there were no tests for the mineral poisons, and handkerchiefs were not in general use.

Frver.

The absence of all knowledge derived from auscultation and percussion makes the chapters upon the diseases of the chest singularly barren, yet Baillie avalled himself of such means of physical examination as were then in use. He recommends that " the heat of the internal parts will be most conveniently measured by putting a small thermometer into the rectum." How much he was in advance of his time in this matter is shown by the following passage from the obituary address by his friend and contemporary, Sir Henry Halford, whosays: "He appeared to lay a great stress upon the information which he might derive from the external examination of his patient, and to be much influenced in the formation of his opinion of the nature of his complaint by this practice. He had originally adopted this habit from the peculiar turn of his early studies; and assuredly such a method, not indiscriminately but judiciously employed, as he employed it, is a valuable auxiliary to the other ordinary means used by a physician of obtaining the knowledge of a disease submitted to him. But it is equally true that, notwithstanding its air of mechanical precision, such examination is not to be depended upon beyond a certain point. Great disordered action may prevail in a part without having yet produced such disorganisation as may be sensibly felt, and to doubt of the existence of a disease because it is not discoverable to the touch is not only unphilosophical, but must surely in many instances lead to unfounded and erroneous conclusions. One of the inevitable consequences of such a system is frequent disappointment in foretelling the issue of the malady, that most important of all points to the reputation of a physician; and though such a method of investigation might prove eminently successful in the skilful hands of Dr. Baillie, it must be allowed to be an example of dangerous tendency to those who have not had his means of acquiring knowledge, nor enjoyed the advantages of his great experience, nor have learned by the previous steps of education and good discipline to reason and judge correctly."

Disease of the Heart.

Baillie knew that "when the heart is much enlarged it is attended with palpitations. These may not only be felt by the band when applied to the left side, but may olten be pereeived by the eye, even when the chest is covered by the ordinary clothing. In one or two instances $I$ have known the pulse at the wrist to beat with an unusual degree of vigour, bat much more commonly the pulse is feeble and irregular. The muscular parietes of the heart being generally very thin in proportion to the enlarged size of its cavities, the heart has little power to propel an increased quantity of blood into the more distant branches of the arterial system. At times there is much difficulty of breathing, and there is a purplish hue of the cheeks and lips. The colour is more deep in its tinge at one time than another, according as the blood has been trangmitted with more or less difficulty through the lungs. The causes which produce a morbid growth of the heart are but little known; one of them would seem to be rheumatism attacking this organ, as Dr. Pitcairn has observed in several cases." A thickening and opacity of the semilunar valves and of the valvular apparatus between the auricles and the ventricles are described correctly enough, and when the auriculo-ventricular valves are thickened the heart is said to be "often found to be considerably enlarged beyond its usual size. I have also seen the valvular apparatus between the auricle and the ventricle in a state of inflamma- 
tion and covered with a layer of coagulable lymph. This I believe to be very uncommon." He then goes on to say that " the symptoms which are produced by a diseased alteration in the structure of the valves of the heart are not so distinct as to be clearly discriminated in practice. They consist of difficulty in breathing; of occasional palpitations; of a weak and often an irregular pulse; and in some cases there has been observed a disposition to fainting. No observations have yet been made by which practitioners may be led to con. jecture what set of valves is diseased."

\section{No Knowledge of Microscopical anatomy.}

The difficulty of pursuing morbid anatomy without the use of a microscope is manifest throughout the book, and it is doubtful whether Dr. Baillie had any clear idea that capillaries nearly always connect the ends of arteries with the beginning of veins. He says, in speaking of blood in the pericardium without a rupture of the heart "blood may have been thrown out by the extremities of the small vessels opening upon the surface chiefly of that portion of the pericardium which forms the intermediate covering of the heart, whose orifices may have been to a very uncommon degree relaxed." In the same manner he thinks that the air found in the stomach may have been "separated from the blood in the blood vessels of the stomach, and poured by the small exhalents into its cavity." The absence of a microscope prevented any knowledge of the minute changes which occur in an inflamed tissue, and caused all hard tumours to be classified together as " scirrhous." Hypertrophy of the prostate, therefore, was called "scirrhous of the prostate," and was not recognised as a disease of old age, whilst uterine fibroids are described as "scirrhous enlargements of the uterus."

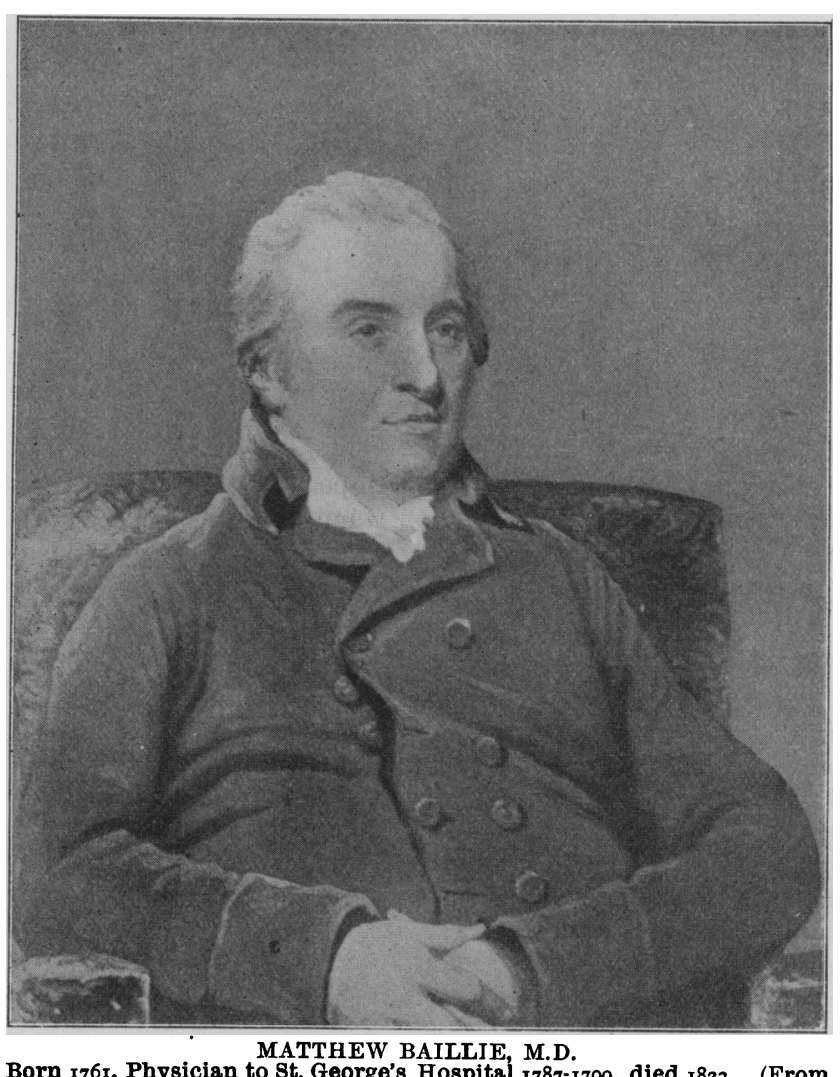

Born 176r, Physician to St. George's Hospital 787-1790, died 823 (From wine. Better results had been obtained with urInary calculi, for the experiments of Dr. Wollaston, the chemist, had enabled them to be grouped into fusible calculi, mulberry calculi, and phosphatic calculi, a basis of classification which is still adopted.

\section{Parasitology.}

Dr. Baillie must at one time have been greatly interested in the subject of comparative anatomy, and, acting probably under the guidance of William Hunter, he had made some original observations in connection with parasitic worms. Two great obstacles stood in the way of a true appreciation of the facts connected with them. The one was that the doctrine of spontaneous generation was atill in full force and all cysts were spoken of as hydatids, and the other that Baillie knew nothing of the alternation of generations which is now $\& 0$ familiar to us. Under the heading of intestinal worms Dr. Baillie describes the ascaris lumbricoides, or as he calls it lumbricus teres. He had dissected it very carefully, and he compares its structuse with that of the earthworm, with whose anatomy he was equally well acquainted, for he even knew something of its nervous system. He alıo describes the tænia solium and bothriocephalus latus, threadworms, and the trichccephalus dispar or trichuris. Speaking of them he says : "There is nothing in the œconomy of animals more obscure than the origin (f intestinal worms; were they found to live out of the bodies of living animals, one might readily suppose that their ovula were taken into the body along with the food and drink, and there gradually evolved into animals. This, however, is not the case; they do not seem to be capable of living any length of time in any situation, except within a living animal body, which appears to be the proper place for their growth and residence. We' might, therefore, be led

The explanation of many pathological processes was made difficult by the teaching that the blood was a living substance in the sense that more active changes took place in it than in the tissues, whereas we know now that the tissues are the more important, and that few pathological changes take place in the blood itself.

\section{Pathological Chemistry.}

The backward state of chemistry in like manner prevented any clear subdivision of the diseases of the kidney. Albu minuria was of course unknown, but curiously enough there is no mention of the appearance of blood in the urine. Dr. Baillie had arrived at the conclusion that gall stones " commonly do not consist of inspissated bile," and that white flaky crystals could be obtaised after boiling them in spirits of to another supposition, namely, that intestinal worms are really formed from the matter contained in the intestines, which previously had no regular organisation; but this idea is widely different from all analogy in the production of animals where there has been any satisfactory opportunity of examining this production. The origin of such animals is a subject of much obscurity, and I do not pretend to throw any light upon it. When the whole evidence, however, in support of the one and the other opinion is compared together, I own that the grounds for believing that in some order of animals equivocal [that is, spontaneous] generation takes place, appear stronger than those for a contrary opinion."

If he was in trouble about parasitic worms, he was in worse trouble about hydatids, for he says: "The origin and rtal nature of hydatids are not fully ascertained; it is extremely 
probable, however, that they are a sort of imperfect animalcules. There is no doubt at all that the hydatids in the livers of sheep are animalcules; they have been often seen to move when taken out of the liver and put into hot water, and they retain this power of motion for a good many hours after a sheep has been killed. The analogy is great between hydatids in the liver of a sheep and in that of the human subject. In both they are contained in strong cysts, and in both they consist of the same white pulpy matter. There is undoubtedly some difference between them in simplicity of organisation; the hydatid in the human liver being a simple uniform bag, and the hydatid in that of the sheep having a neck and mouth appended to the bag. This difference need be no considerable objection to the opinion above stated. Life may be conceived to be attached to the most simple form of organisation. The probability of their being animalcules is very strong; and it appears even more difficult to account for their production according to the common theory of generation than for that of intestinal worms." Yet knowing this, or perhaps biassed by it, we find the only piece of really faulty observation to which he has committed himself in the following passage in the volpme of Engravings to which reference has been made above: "A portion of a placenta is here represented which had been converted into hydatids. It had belonged to an ovum which was not far advanced-namely, to about the third or fourth month. It is not uncommon for every part of an ovum except the fœitus to have hydatids Tormed in it, and these put on a different appearance from the hydatids which grow in the human liver. They are oval in shape, and have a very narrow neck or process running out from one extremity of them. Their coats are thinner than those of hydatids of the liver, and they are not enclosed like them in hard cysts. They possess a procreative power, and smaller hydatids are often to be seen attached to the coats of the larger ones. They appear to have the same claim with hydatids of the liver to be considered as animals of a very simple structure."

\section{General accuracy with Many Defiomencies.}

It is clear from the foregoing extracts that the morbid anatomy learnt by students a hundred years ago was essentially modern in tone, and was for the most part accurate. The curious thing about it was the huge gaps which remained to be filled. Pneumonia and the changes produced by it in the lungs are dismissed very summarily. The lungs are said " to be sometimes converted into a solid substance very much resembling the liver, but I have only seen an example of this change in a preparation, and $I$ am inclined to believe that it had been produced by a wide-extended inflammation, in which a large quantity of coagulable lymph had been extravasated into the substance of the lungs." In the same way emphysema is almost neglected. Dr. Baillie says, "In opening into the chest it is not unusual to find that the lungs do not collapse but that they fill up the cavity completely on each side of the heart. When examined their cells appear full of air, so that there is seen upon the surface of the lungs immediately under the pleura a prodigious number of small white vesicles. The branches of the trachea are often at the same time a good deal flled with a mucous fluid."

There is one passage which may be read to convey a suggestion of typhoid ulcers, for in speaking of inflammation of the intestine he says: "In the follicular glands, which are gathered together in little oval groups, I think ulceration occurs more frequently than in other parts of the intestine."

Students in England were fortunate, therefore, in having so good a teacher as Dr. Baillie, who in turn owes much of the success of his Iilustrations of Morbid Anatomy to the "drawings made by a young man, who is not only well skilled in his own art, but who possesses a considerable share of knowledge in anatomy." The name of the artist is not mentioned, but on turning to the plates each is signed "W. Clift," first the amanuensis, then the friend of John Hunter, afterwards the faithful guardian of his collection, whose daughter married Sir Richard Owen.

Pathology in Scotrand.

At the beginning of the century it was only in England that pathology had become a separate subject. In Scotland it was still combined with physiolog: and therapeutics under the general heading of "The Institutes of Medicine." Dr. Andrew Duncan in 1782 issued a small volume entitled Heads of Lectures on Pathology, but his notes show that he taught upon the old lines, and was dealing with a highly speculative science instead of with one based upon morbid anatomy. The lectures were extra-academical, and attracted a large number of students, but it was not until 1789 that Duncan succeeded to the chair held by James Gregory, whose election he had contested in 1776. The University Chair of Pathology was not founded until 1831 , the first professor being John Thomson, father of Professors William and Allen Thomson, but it was not until nearly the middle of the century that any separate textbook on modern pathology was published.

Pathology in JRhLaNd.

In Ireland things were still more backward, and Piofessor Macalister, in his recent memoir of James Macartney, has given a lively picture of the state of the profession in Dublin a hundred years ago. Macartney transcribed a series of "Opinions Peculiar to Mr. Dease, Professor of Surgery in the College of Surgeons, advanced in his course, 1796." Amongst these Professor Macalister quotes, "the brain is an inorganic mass, devoid of sensibility and irritability, secreted by the arteries of the pia mater, and consequently incapable of inflammation; that polypi in the nose, like other animals, have their infancy, maturity, and death." John Cheyne, however, Professor of Medicine, $1813^{-19}$, in the University of Dablin, devoted himself more particularly to the study of pathology, and with the assistance of Dr. Robert Percival, the Professor of Chemistry, established a museum of morbid anatomy in connection with the House of Industry Hospitals.

\section{fttèiritite int 1800 .}

By T. CLIFFORD ALLBUTT, M.D., F.R.S., Regius Professor of Physic in the University of Cambridge.

THE Editor has asked me to describe the state of medicine at the beginning of the nineteenth century, and has pointed out that the works of Cullen are worthy of regard as a monument of that time. Cullen's First Lines of the Practice of Physio was published first in 1769, and went through many subsequent editions, until in 1827 an excellent edition of Cullen's works was published in two volumes by Dr. John Thomson of Edinburgh; this edition $I$ have used in the preparation of the present article. Cullen was born in 1712, and died in 1790

In the history of thought we find that after periods of $\in \overline{-}$ travagant speculation, whether in the direction of realism or of mysticism, or indeed of a sounder philosophy of a literary or academic kind, a phase of "common sense" sets in. With this phase, if he come to hear of it, the ordinary man is 